\title{
Efficient Determination and Evaluation of Model Cyclodextrin Complex Binding Constants by Electrospray Mass Spectrometry
}

\author{
Yannis Dotsikas and Yannis L. Loukas \\ Department of Pharmaceutical Chemistry, School of Pharmacy, University of Athens, Athens, Greece
}

\begin{abstract}
Electrospray ionization mass spectrometry (ESI-MS) is now routinely used for the detection of cyclodextrin noncovalent complexes, complementing previously established methods. Hostguest complexes formed in solution are also stable for characterization by ESI in the gas phase. This paper reports the first investigations to characterize the stability of three inclusion complexes between $\beta$-cyclodextrin ( $\beta$-CD) and three model "guest" molecules, by determining the cyclodextrin compound complex stability constant $\left(K_{\mathrm{st}}\right)$ with the use of mass spectrometric studies. The relative signal intensity of the complexes were monitored in the positive ion mode by mixing each "guest" molecule with an up to 50-fold molar excess of $\beta C D$. A novel linear equation, similar to Benesi-Hildebrand, was derived allowing the determination of $K_{\text {st }}$ for 1:1 stoichiometry in all complexes. These values were compared with the $K_{\text {st }}$ obtained by spectrophotometric experiments and they were evaluated to be slightly different, indicating the validity of the described method. (J Am Soc Mass Spectrom 2003, 14, 1123-1129) (C) 2003 American Society for Mass Spectrometry
\end{abstract}

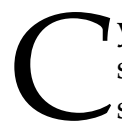
yclodextrins (CDs) [1] are crystalline, nonhygroscopic, cyclic oligosaccharides derived from starch. Natural CDs $\left(\alpha-, \beta-\right.$, and $\left.\gamma_{-}\right)$and their derivatives are of prime interest as stabilizing and solubilizing systems, enzyme models, catalysts, stationary and mobile phase additives for chiral and isomeric separations, and so on [2-4]. CDs are torus-shaped and dissolved in water, the hydroxyl groups arrange on the outer surface of the ring, resulting in an internal cavity that is relatively hydrophobic, consisting of a circular configuration of hydrogen atoms and glucoside oxygen atoms. This arrangement permits CDs to accommodate the hydrophobic part of a guest molecule within the cavity [5] and so forming an "inclusion complex", while hydrophilic parts tend to maximize their contact with the polar solvent. The fit of the entire or at least part of the guest molecules in the "host" cavity determines the stability of the complexes formed and the selectivity of the complexation process.

Because of their inherent usefulness, different studies have been performed to evaluate the complexation procedure, the stability (binding) constant, and the stoichiometries of the complexes. A number of different physicochemical methods are described in the literature for determination of the stability constant based on techniques such as ${ }^{1} \mathrm{H}$ NMR, conductometric titrations,

Published online August 28, 2003

Address reprint requests to Dr. Y. L. Loukas, Department of Pharmaceutical Chemistry, School of Pharmacy, University of Athens, Panepistimioupoli Zografou GR-157 71, Athens, Greece. E-mail: loukas@pharm.uoa.gr potentiometric, spectrophotometric and fluorometric methods, solubility, kinetic studies, and competitive indicator binding [6-11]. Most of these assume a 1:1 molar ratio between cyclodextrin and the guest molecule of interest. However, there have been reported studies in which two or more cyclodextrins can bind to a single guest molecule and the overall model is significantly altered in multiple cyclodextrin complexes. It is becoming evident that assuming the complex stoichiometry without having adequate experimental results can lead to erroneous determinations of the stability constant values [12]. For example, in the literature one group [13] assumes 1:1 complexation between prostaglandin $\mathrm{B}_{1}$ with $\alpha \mathrm{CD}$ and another group [14] 1:2, with significant deviation in their results $\left(1430 \mathrm{M}^{-1}\right.$ and 144 $\mathrm{M}^{-1}$, respectively, for $K_{\mathrm{st}}$ values). Subsequently, almost all of the techniques reported previously require initial experiments for the calculation of the complex stoichiometry. The previous limitation, plus the limited sensitivity, the limited solvent compatibility, and the lack of structural information, have highlighted the need for mass spectrometric studies [15].

Electrospray ionization mass spectrometry (ESI-MS) provides a powerful means to study noncovalent "hostguest" inclusion complexes between a cyclodextrin and a molecule [16-19]. The mild ionization procedure allows the survival of their solution state structure and their presence in the gas phase seems to take place [20] - although this question is not fully settled-without the requirement that the sample be volatile and in a solvent-free environment. An important issue that has 
been addressed in several studies is whether the observed peaks represent actual inclusion complexes or rather electrostatic adducts [21] formed during the electrospray process. Their conclusion was based on the presence of complexes in the mass spectra from hydrophilic guest molecules that they believed could not form inclusion complexes in solution. These results suggest that "false positives" inclusion complexes should be precluded by applying other techniques to prove the complex formation. Since then, different studies have been reported that evidenced the existence of gas-phase inclusion complexes involving methods such as collision-induced dissociation [15, 18, 22], blackbody induced radiation dissociation [23], heated capillary dissociation [24], and mainly by guest-exchange reactions in gas phase with a $C D$ host sensitive to the chirality of the amino acid guest [20, 25, 26].

The use of ESI for characterizing the strength of interactions between synthetic or biological hosts and guests has been a growing area of research lately. A number of methods have been proposed for the measurement of binding selectivities and constants of various noncovalent complexes in the gas phase. Most of them have dealt with crown ethers and their analogues that form complexes with alkali metal ions [27, 28], oligonucleotide-serum albumin complexes [29], protein-phosphopeptide complexes [30], vancomycin-peptide complexes [31-33] and aminoglycoside-RNA models [34]. Most of the methods entail monitoring the intensities of all species and estimating various $\log K$ values by using titrimetric data to construct a Scatchard-style plot [29, 30, 32-34] for a range of concentrations. Another method assumes that ESI efficiencies of the various host-guest complexes and unbound species are similar [31]. A related method [35] involves the use of an internal standard to account for the differences in ESI efficiencies of the complexes. The most recent method involves a competitive equilibrium experiment in which the intensity of the complex is monitored after the addition of a second host or guest to perturb the equilibrium distribution of complexes and the construction of another type calibration curve [36]. In many cases, remarkably good agreement between the gasphase and solution-phase studies regarding various noncovalent interactions was observed [37-39].

In the present study, a well known approach from other techniques was employed. In brief, the differences in the relative intensity of the complex (elsewhere absorbance, fluorescence intensity etc.) due to the complex formation, were mathematically correlated with the increasing concentrations of $\beta \mathrm{CD}$ and the stability constant. The selection of the guest molecules, 4-(1imidazolyl)phenol (4-IMP) (Figure 1a), 3-hydroxybenzylhydrazine (3-HBH), and 2-furoic hydrazide (2-FUH) (Figure 2) was based on their structural features that favor binding with the $\mathrm{CD}$ cavity and provide intense signal during the ESI process. Phenyl ring is a hydrophobic moiety which fits well into the cavity of $\beta C D$ and its derivatives form numerous stable complexes. In a)

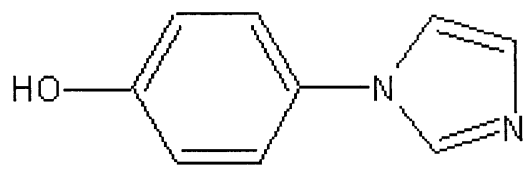

b)

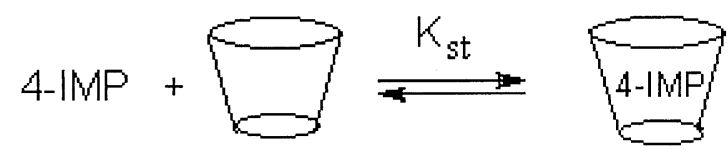

$G$
$\mathrm{G} \cdot \mathrm{CD}$

Figure 1. (a) Chemical structure of the guest 4-(1-imidazolyl)phenol. (b) Schematic representation of 1:1 complex formation between 4-IMP and $\beta C D$.

addition, the existence of amino, hydroxyl and carbonyl groups in the guest molecules allows interactions with the hydrophilic parts of the outer surface of $\beta C D$ via hydrogen bonding, providing further stabilization to the superior hydrophobic interactions. Consequently, quite large values $\left(\sim 1000 \mathrm{M}^{-1}\right.$ or higher) of the stability constant for the examined 1:1 complexes could be expected. In an attempt to examine the validity of the proposed method, spectrophotometric experiments were performed and the determined binding constants did not differ significantly in both methods.

\section{Experimental}

\section{Chemicals}

4-(1-imidazolyl)phenol $\left(\mathrm{M}_{\mathrm{r}}=160.2\right)$ and 2-furoic hydrazide $\left(\mathrm{M}_{\mathrm{r}}=126.1\right)$ were purchased from Aldrich $(\mathrm{Mu}-$ nich, Germany). 3-hydroxybenzylhydrazine $\left(\mathrm{M}_{\mathrm{r}}=\right.$ 138.2) was purchased from Fluka (Munich, Germany). $\beta$-cyclodextrin $\left(\mathrm{M}_{\mathrm{r}}=1134.9\right)$ was obtained from Wacker-Chemie GmbH (Munich, Germany). All other materials (Methanol, acetic acid) were obtained from Sigma Chemical Co. (St. Louis, MO) and were of analytical grade. Deionized and doubly distilled water was obtained from a Millipore Milli-Q Plus System, Malva, Athens, Greece (Resistivity $>18 \mathrm{M} \Omega \mathrm{cm}$ ).

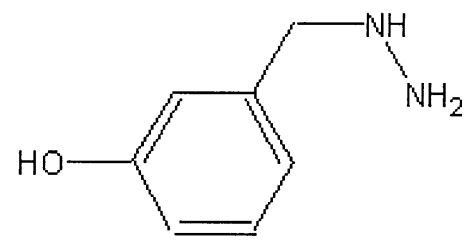

3-HBH

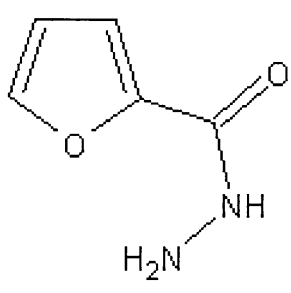

2-FUH

Figure 2. Chemical structure of the other two guests; 3-hydroxybenzylhydrazine and 2-furoic hydrazide. 
Table 1. Linear equations and calculated stability constant values for the complexes of the three model guests with $\beta C D$

\begin{tabular}{llrrr}
\hline & Linear equation & $\mathrm{r}^{2}$ & $\mathrm{~K}_{\text {st }}$ & $\mathrm{K}_{\text {st }}(\mathrm{UV})$ \\
\hline \hline 4-IMP* $^{*} \mathrm{IMBH}^{*}$ & $\left(1 / \Delta \mathrm{I}_{\mathrm{r}}\right)=0.0097\left(1 /[\mathrm{CD}]_{\mathrm{t}}\right)-13.95$ & 0.9974 & $1438( \pm 75)$ & $1281( \pm 61)$ \\
$3-\mathrm{HBH}^{*}$ & $\left(1 / \Delta I_{\mathrm{r}}\right)=0.0112\left(1 /[\mathrm{CD}]_{\mathrm{t}}\right)-12.14$ & 0.9905 & $1084( \pm 58)$ & $1112( \pm 55)$ \\
$2-\mathrm{FUH}^{*}$ & $\left(1 / \Delta \mathrm{I}_{\mathrm{r}}\right)=0.0121\left(1 /[\mathrm{CD}]_{\mathrm{t}}\right)-10.97$ & 0.9952 & $906( \pm 43)$ & $820( \pm 38)$ \\
\hline
\end{tabular}

*All values are mean of 3 measurements $( \pm S D)$.

\section{Mass Spectrometry}

All experiments were performed on an AQA LC/MS system (Finnigan, Thermoquest, Les Ulis Cedex, France) equipped with an Electrospray ionization source, a quadrupole mass analyzer and the suitable interface (Xcalibur Data System, Manchester, UK). All samples were transferred from AQA reservoir to ESI probe via a fused silica capillary by pressurizing the reservoir. A pressure of approximately $6 \mathrm{psi}$ was needed to produce the desired flow rate of $10 \mu \mathrm{l} / \mathrm{min}$ for infusion. The probe heater temperature was set at $140{ }^{\circ} \mathrm{C}$ and probe and cone voltages were held at 3500 and $35 \mathrm{~V}$, in positive ion mode, respectively.

Data was acquired across mass range $100-1340 \mathrm{~m} / \mathrm{z}$, since above $m / z$ value 1340 (and <2000) no strong peaks were detected in all cases (that denotes only 1:1 and not 1:2 CD:guest complex formation ). Considering the very small size of the selected guests and the relatively low excess of $\beta C D$, the possibility of a 2:1 (CD:guest) complex formation must be precluded. This assumption was also evidenced by Job plot experiments with UV measurements (data not shown) [11]. For each mass spectrum, 50 scans were summed, in order to achieve a high signal-to-noise ratio and good statistics for signal intensities and the obtained spectra were recorded. To avoid contamination between runs (memory effect) the capillary and the ESI needle were washed with several milliliters of methanol.

\section{Evaluation of the Complexation Procedure}

Complexation of 4-IMP, 3-HBH, and 2-FUH with $\beta \mathrm{CD}$ was monitored by ESI in the presence of increasing concentrations of $\beta C D$. A stock solution of each guest in

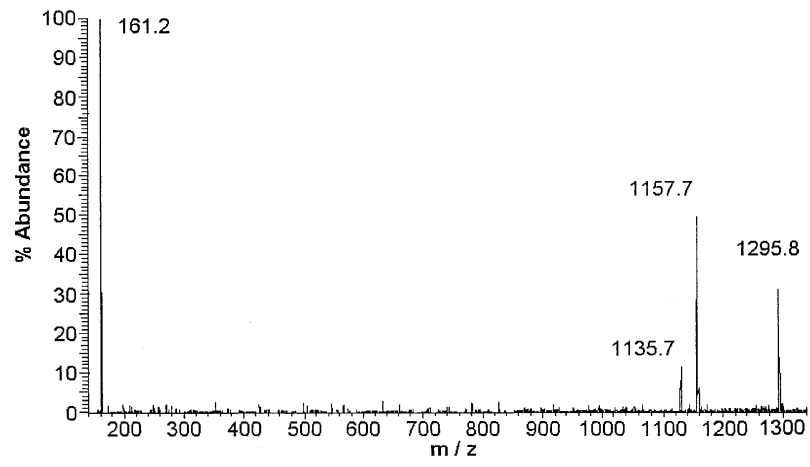

Figure 3. Full scan positive ESI mass spectrum obtained for a 1:40 (4-IMP: $\beta C D$ ) molar ratio in $\mathrm{MeOH} / \mathrm{H}_{2} \mathrm{O} /$ acetic acid (45/45/ 10 , vol/vol) solution.
$\mathrm{MeOH} / \mathrm{H}_{2} \mathrm{O} /$ acetic acid $(45 / 45 / 10, \mathrm{vol} / \mathrm{vol})$ was prepared and a standard quantity of it was added to solutions with the same solvent composition containing increasing concentrations of $\beta C D$ in a varying ratio from 1:1 to 1:50. All solutions had the same initial guest concentration $\left(2 \times 10^{-5} \mathrm{M}\right)$ which was finally equal to the sum of concentrations of free and complexed molecule. During a designated time of incubation $(1 \mathrm{~h})$ at room temperature, the sample solutions were stirred periodically. Afterwards all samples were transferred into $1.5 \mathrm{ml}$ Eppedorf tubes and analyzed as previously described. All experiments were performed in triplicate for every guest:CD ratio.

\section{Results and Discussion}

Initially, spectrophotometric studies were performed in order to prove complexes formation by measuring the difference in absorbance due to complexation, and applying the Benesi-Hildebrand equation (data not shown) $[9,10]$. The results suggested the formation of three very stable 1:1 complexes; their stability constant values are presented in Table 1 .

All representative ESI/MS spectra acquired from a solution containing each guest, $\beta \mathrm{CD}$ (in the molar ratio of 1:40) and their 1:1 complexes are shown in Figures 3, 4 , and 5. Four main ions were detected in each spectrum; e.g., in case of 4-IMP, ions at $m / z$ 161.2, 1135.7, $1157.7,1295.8$ correspond to protonated 4-IMP, protonated species of $\beta C D$, sodiated species of $\beta C D$ and protonated species of 4-IMP: $\beta C D$ complex, respectively. The low intensity, despite the high concentration, of protonated species in the acidic media, is indicative that $\beta C D$ does not actually contain ionizable groups. Sodium (an impurity in the solvents and chem-

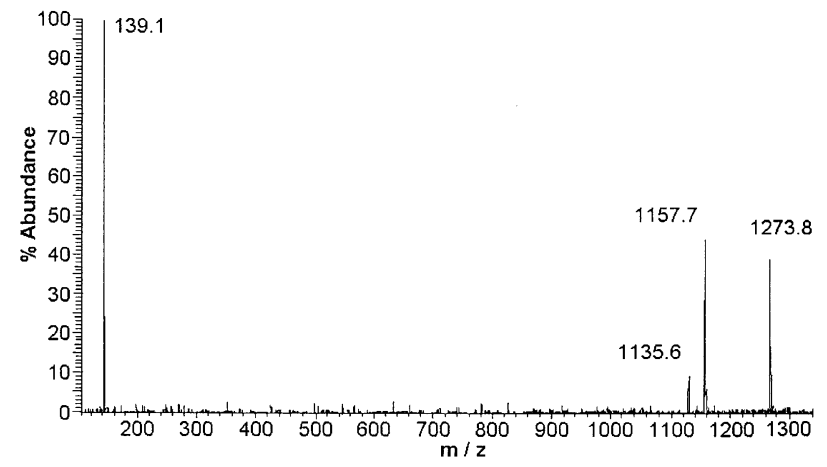

Figure 4. Full scan positive ESI mass spectrum obtained for a 1:40 (3-HBH: $\beta C D)$ molar ratio in $\mathrm{MeOH} / \mathrm{H}_{2} \mathrm{O}$ /acetic acid (45/45/ $10, \mathrm{vol} / \mathrm{vol}$ ) solution. 


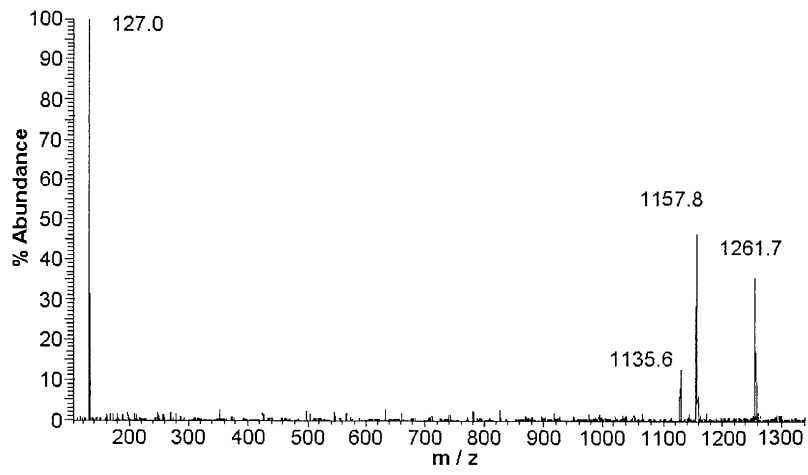

Figure 5. Full scan positive ESI mass spectrum obtained for a 1:40 (2-FUH: $\beta C D)$ molar ratio in $\mathrm{MeOH} / \mathrm{H}_{2} \mathrm{O} /$ acetic acid (45/45/ 10 , vol/vol) solution.

icals used) adducts are probably formed because of electrostatic binding to hydroxyl groups of $\beta C D$. It is worth mentioning that similar experiments in a $20 /$ $70 / 10$ (vol/vol) $\mathrm{MeOH} / \mathrm{H}_{2} \mathrm{O} /$ acetic acid solution did not alter the qualitative observations presented below.

Considering a 1:1 system (G:CD) (Figure $1 \mathrm{~b}$ ) with the guest (e.g., 4-IMP) (G), and $\beta \mathrm{CD}(\mathrm{CD})$ at total concentrations of $\mathrm{G}_{\mathrm{t}}$ and $\mathrm{CD}_{\mathrm{t}}$, respectively, the equilibrium constant $K_{\mathrm{st}}$ can be calculated as follows:

$$
K_{\mathrm{st}}=\frac{[\mathrm{G}: \mathrm{CD}]}{[\mathrm{G}][\mathrm{CD}]} \Rightarrow[\mathrm{G}: \mathrm{CD}]=K_{\mathrm{st}}[\mathrm{G}][\mathrm{CD}]
$$

The mass balance equations for $\mathrm{G}$ and $\mathrm{CD}$ are:

$$
\begin{aligned}
& \mathrm{G}_{\mathrm{t}}=[\mathrm{G}]+[\mathrm{G}: \mathrm{CD}] \\
& \mathrm{CD}_{\mathrm{t}}=[\mathrm{CD}]+[\mathrm{G}: \mathrm{CD}]
\end{aligned}
$$

The free guest concentration [G] is obtained by substituting eq 1 into eq 2

$$
[\mathrm{G}]=\frac{\mathrm{G}_{\mathrm{t}}}{1+K_{\mathrm{st}}[\mathrm{CD}]}
$$

As the concentration of $\beta C D$ increases from sample to sample, the intensity of the product (complex) $I_{c}$ increases and on the contrary the intensity of the reactant (guest) $I_{\mathrm{G}}$ decreases. The decrease in the intensity of $\mathrm{G}$, when the excess of $\beta C D$ rises, was not similar to the increase of the complex intensity. The two ions have totally different sizes and solvation energies [40] and subsequently ESI efficiencies.

A first attempt to correlate directly the complex intensity with the fraction of the complexed guest led to erroneous calculations with relatively large deviations, especially for samples with a high excess of $\beta C D(40 \times$ and $50 \times)$. The high concentration of $\beta C D$ in the droplets had a significant effect on the generation of all ions in the ESI process, resulting in ion signal saturation due to insufficient ionization (droplet charge formation)

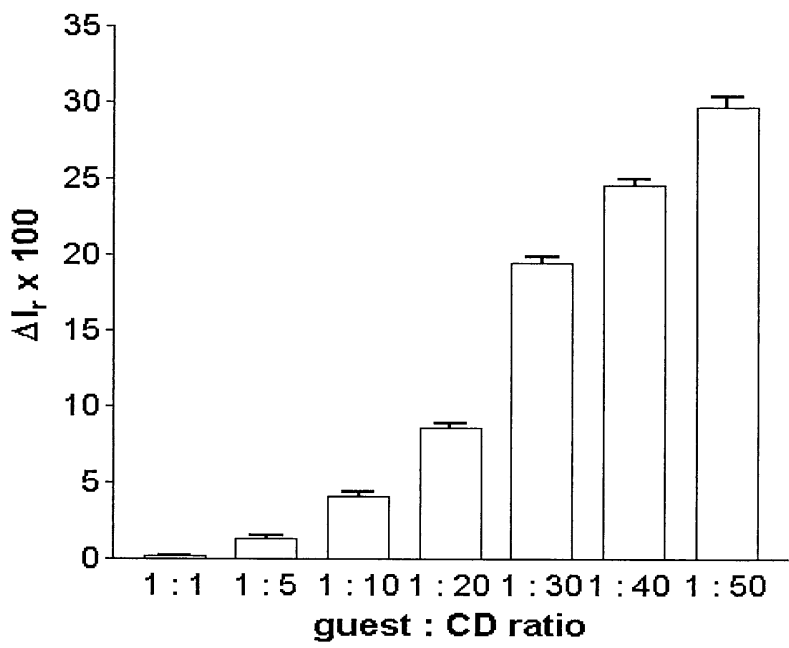

Figure 6. Relative intensities $\left(\Delta \mathrm{I}_{\mathrm{r}}\right)$ of the 1:1 complex between 4 -IMP and $\beta C D$ for all host:guest ratio samples $(n=3)$.

[41]. In addition, different ESI efficiencies may require the evaluation of "ESI response factors" for different species into quantitative measurements.

The intensity of the complex is therefore better reported relative to the sum of intensities of the complex and the guest. This approach [26] comprises the use of the Relative intensity $I_{\mathrm{r}}$ of the complex as a response of the complexed concentration of G. $I_{\mathrm{r}}$ is defined as follows: $I_{\mathrm{r}}=I_{\mathrm{c}} / I_{\mathrm{tot}}$, where $I_{\mathrm{tot}}=I_{\mathrm{c}}+I_{\mathrm{G}}$. As Figure 6 indicates, the repeatability of the measurements is excellent for all samples. Using linear regression, a calibration curve could be obtained that correlates the increase of $I_{\mathrm{r}}$ with [CD] and $K_{\mathrm{st}}$. The latter is determined from the equation that fits the calibration curve.

In every CD:guest ratio the relative complex intensity is

$$
I_{r}=k_{\mathrm{c}}[\mathrm{G}: \mathrm{CD}]
$$

where $k_{\mathrm{c}}$ is the proportionality constant. The relative intensity of the complex is obtained by substituting eqs 1 and 4 into eq 5, leading to an equation in which $I_{\mathrm{r}}$ is directly related to $[C D]$ :

$$
I_{r}=k_{\mathrm{c}} K_{\mathrm{st}}[\mathrm{CD}] \frac{\mathrm{G}_{\mathrm{t}}}{1+K_{\mathrm{st}}[\mathrm{CD}]}
$$

The complexation process is expressed with the difference $\Delta I_{\mathrm{r}}=I_{\mathrm{r}}-I_{\mathrm{o}} \approx I_{\mathrm{r}}$, as the initial intensity of the complex is practically zero. Eq 6 can be thus rewritten as:

$$
\Delta I_{r}=k_{\mathrm{c}} K_{\mathrm{st}}[\mathrm{CD}] \frac{\mathrm{G}_{\mathrm{t}}}{1+K_{\mathrm{st}}[\mathrm{CD}]}
$$

At this point the assumption that $[C D]=C_{t}$ is employed (when a high excess of $C D_{t}$ is being used 
compared to $G_{t}$ ). Finally, eq 7 is transformed into a double reciprocal linear equation, similar to BenesiHildebrand one, that correlates the observed differences $\left(\Delta I_{\mathrm{r}}\right)$ in the relative complex intensity and the initial total concentrations of the guest and $\beta \mathrm{CD}$ :

$$
\frac{1}{\Delta I_{r}}=\frac{1}{k_{\mathrm{c}} \mathrm{G}_{\mathrm{t}} K_{\mathrm{st}}[\mathrm{CD}]_{\mathrm{t}}}+\frac{1}{k_{\mathrm{c}} \mathrm{G}_{\mathrm{t}}}
$$

The stability constant for each complex was obtained from the intercept and slope of a weighted least-squares regression fit of the data to eq 8 (Figure 7) for samples with a molar ratio CD:guest $\geq 5$. The $\mathrm{r}^{2}$ values for the fit were $>0.9900$ in all cases, indicating an excellent correlation between the logistic equation and experimental values. The calculations gave $K_{\mathrm{st}}$ values that are presented in Table 1. It is obvious that the calculated values were slightly different from the $K_{\text {st }}$ values obtained from spectrophotometric studies. This agreement was another promising factor in this initial attempt to measure these binding constant values with mass spectrometric data, but it was not necessary. Actually, the variability between methods is a common phenomenon [12] and is attributed to the specific characteristics of each method. In addition, a comparison of the magnitude of the estimated values leads to logical conclusions, e.g., 4-IMP is expected to form more stable

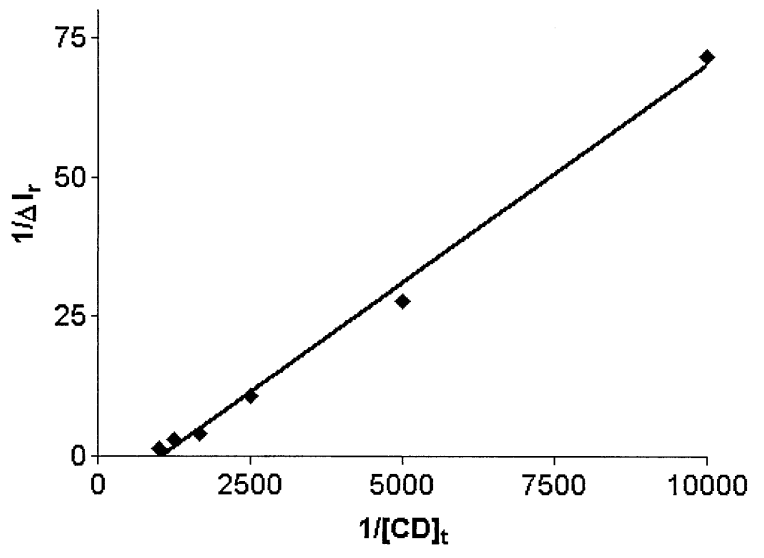

Figure 7. Linear plot of eq 8 showing the effect of $\beta C D$ on the relative signal intensity $\left(\Delta \mathrm{I}_{\mathrm{r}}\right)$ of 4 -IMP: $\beta C D$ complex.

complex with $\beta \mathrm{CD}$ than $3-\mathrm{HBH}$ or 2 -FUH does, since 3-HBH has a substituent in 3-position of the phenol and 2-FUH has a smaller ring.

Avoiding the above assumption $\left([C D]=C_{t}\right)$, different processes were followed resulting in a mathematical model which does not contain any approximations and have much broader applicability (e.g., complexes with all stoichiometries). After performing suitable transformations [42], the following equation is derived:

$$
\Delta I_{r}=\frac{\mathrm{G}_{\mathrm{t}} k_{\mathrm{c}}\left\{-\left(K_{\mathrm{st}} \mathrm{G}_{\mathrm{t}}-K_{\mathrm{st}} \mathrm{CD}_{\mathrm{t}}+1\right) \pm \sqrt{\left(K_{\mathrm{st}} \mathrm{G}_{\mathrm{t}}-K_{\mathrm{st}} \mathrm{CD}+1\right)^{2}+4 K_{\mathrm{st}} \mathrm{CD}_{\mathrm{t}}}\right\}}{2-\left(K_{\mathrm{st}} \mathrm{G}_{\mathrm{t}}-K_{\mathrm{st}} \mathrm{CD}_{\mathrm{t}}+1\right) \pm \sqrt{\left(K_{\mathrm{st}} \mathrm{G}_{\mathrm{t}}-K_{\mathrm{st}} \mathrm{CD} D_{\mathrm{t}}+1\right)^{2}+4 K_{\mathrm{st}} \mathrm{CD}_{\mathrm{t}}}}
$$

Eq 9 is solved iteratively and the erroneous solution (either negative or redundant) is discarded. The nonlinear model gave a value of $1381 \mathrm{M}^{-1}$ for the stability constant of 4-IMP, including data from all samples. Our experience has shown that non-linear models like the previous one can be applied for the calculation of the binding constants in all types of complexes and especially in multiple complex formation. However, in case of a complex with 1:1 stoichiometry a series of linear procedures could be used without hesitations, since the deviation in values are in the acceptable range and their application is much easier.

In the present experiments the formation of nonspecific adducts can't be precluded, but in any case their effect on the performed experiments did not affect the calculations, as shown from the excellent linearity of eq 8 and the agreement with the value obtained spectroscopically. However, in cases where nonspecific aggregation occurs in a high degree, the study of these complexes by using the total intensity may appear to be tricky and therefore it is proposed to apply the method presented by Gabelica and coworkers [43] to estimate the contribution of nonspecific adducts. The formation of 2:2 guest:CD complexes can not be precluded, although the features of the selected guests minimize this possibility. In this case the doubly-charged 2:2 adducts have the same nominal $\mathrm{m} / \mathrm{z}$ values as singly-charged 1:1 complexes and would contribute to 1:1 complex intensity. However, in the present experiments this contribution could be considered, without hesitations, as unimportant.

The present study shows the utility of ESI-MS to predict the behavior of a complexing agent with CDs and evaluate the strength of their interactions, and thus gives another quantitative means of measuring the binding properties. Undoubtedly, the basic condition for this is that the guest and host-guest complexes are ionic or could easily become ionic and consequently may be detected by the mass spectrometer. One could consider the use of ESI-MS as the method of choice for studying this kind of complex, since it provides major advantages that could not be found elsewhere: (1) It indicates complex stoichiometry automatically, and (2) it is the only technique that can describe with accuracy the interaction of a guest molecule with derivitized CDs that have a different degree of substitution [44]. In fact, it has been proven that the presence of additional chains outside the CD cavity has a major effect on the complexation. Considering that these chemically modified CDs are commercially available as a mixture of products with different degrees of chain substitution, their use without previous separation and the evaluation of the complexation parameters with other techniques [45] has a theoretical meaning, since they indicate the be- 
havior of an "average" structure. Only advanced ESI-MS experiments can evaluate the effect of each chain on the complexation characteristics by monitoring the relative intensity of each complex. We intend to provide, in an upcoming report, studies dealing with this issue.

\section{Conclusion}

In the present study, the basic concept in which the difference in a physical parameter can be directly related to the complex concentration and allow the determination of the complex binding constant was successfully applied in LC/MS as in other analytical techniques before.

The ESI-MS method was found to be a convenient way to evaluate the binding constant of guest:CD complexes. After ensuring the complex formation with another technique, a novel lineal equation was presented that correlated the stability constant value with the total concentration of the $\mathrm{CD}$, allowing the evaluation of this parameter. This report showed the validity and applicability of using ESI-MS as an alternative to conventional methods to gain information about the strength of a variety of noncovalent inclusion complexes and avoid their associated shortcomings. Therefore, ESI-MS could be the method of choice to characterize all complexes that can be detected by the mass spectrometer and provide additional information.

\section{References}

1. Szejtli, J. Cyclodextrins. Properties and Applications. Drug Investig. 1990, 2, 11-21.

2. Hedges, A. R. Industrial Applications of Cyclodextrins. Chem. Rev. 1998, 98, 2035-2044.

3. Szejtli, J. Introduction and General Overview of Cyclodextrin Chemistry. Chem. Rev. 1998, 98, 1743-1753.

4. Loukas, Y. L. Understanding Molecular Association and Isomers Recognition in Isomer-Cyclodextrin Multiple Complex Formation by Improved Liquid Chromatographic Studies. Anal. Chem. 1998, 70, 966-970.

5. Loukas, Y. L.; Jayasekera, P.; Gregoriadis, G. Characterization and Photoprotection Studies of a Model $\gamma$-Cyclodextrin-Induced Photolabile Drug Entrapped in Liposomes Incorporating Light Absorbers. J. Phys. Chem. 1995, 99, 11035-11040.

6. Bongiorno, D.; Ceraulo, L.; Mele, A.; Panzeri, W.; Selva, A. Turco; Liveri, V. Structural and Physicochemical Characterization of the Inclusion Complexes of Cyclomaltooligosaccharides (Cyclodextrins) with Melatonin. Carbohydr. Res. 2002, 337, 743-754.

7. Connors, K. A.; Pendergast, D. D. Microscopic Binding Constants in Cyclodextrin Systems: Complexation of $\alpha$-Cyclodextrin with Sym-1,4-Disubstituted Benzenes. J. Am. Chem. Soc. 1984, 106, 7607-7614.

8. Loukas, Y. L. Multiple Complex Formation of Fluorescent Compounds with Cyclodextrins: Efficient Determination and Evaluation of the Binding Constant with Improved Fluorometric Studies. J. Phys. Chem. B 1997, 101, 4863-4866.

9. Loukas, Y. L.; Antoniadou-Vyza, E.; Valiraki, A. P. Inclusion Complexes and Stability Studies of an Organophosphorus Insecticide with Cyclodextrins: Spectrophotometric and Ki- netic Determination of Stability Constant. Analyst 1995, 120, 533-538.

10. Loukas, Y. L. Measurement of the Molecular Association in Drug-Cyclodextrin Inclusion Complexes with Improved ${ }^{1} \mathrm{H}$ NMR Studies. J. Pharm. Pharmacol. 1997, 49, 944-948.

11. Dotsikas, Y.; Kontopanou, E.; Allagiannis, C.; Loukas, Y. L. Interaction of 6-p-Toluidinylnaphthalene-2-Sulphonate with $\beta$-Cyclodextrin. J. Pharm. Biomed. Anal. 2000, 23, 997-1003.

12. Loukas, Y. L. Evaluation of the Methods for the Determination of the Stability Constant of Cyclodextrin-Chlorambucil Inclusion Complexes. J. Pharm. Biomed. Anal. 1997, 16, 275-280.

13. Uekama, K.; Hirayama, F.; Ikeda, K.; Inaba, K. Utilization of Cyclodextrin Complexation for Separation of E, A, and B Prostaglandins by Ion-Exchange Liquid Chromatography. J. Pharm. Sci. 1977, 66, 706-710.

14. Armstrong, D. W.; Nome, F.; Spino, L. A.; Golden, T. D. Efficient Detection and Evaluation of Cyclodextrin Multiple Complex Formation. J. Am. Chem. Soc. 1986, 108, 1418-1421.

15. Selva, A.; Redenti, E.; Zanol, M.; Ventura, P.; Casetta, B. A Study of $\beta$-Cyclodextrin and Its Inclusion Complexes with Piroxicam and Terfenadine by Ionspray Mass Spectrometry. Org. Mass Spectrom. 1993, 28, 983-986.

16. Cheng, Y.; Hercules, D. M. Measurement of Chiral Complexes of Cyclodextrins and Amino Acids by Electrospray Ionization Time-of-Flight Mass Spectrometry. J. Mass Spectrom. 2001, 36, 834-836.

17. Lamcharfi, E.; Chuilon, S.; Kerbal, A.; Kunesch, G.; Libot, F. Virelizier H. Electrospray Ionization Mass Spectrometry Supramolecular Chemistry: Characterization of Noncovalent $\mathrm{Cy}-$ clodextrin Complexes. J. Mass Spectrom. 1996, 31, 982-986.

18. Bakhtiar, R.; Hop, C. E. C. A. A Study of the Complexation Between Dimethyl- $\beta$-Cyclodextrin and Steroid Hormones Using Electrospray Ionization Mass Spectrometry. Rapid Commun. Mass Spectrom. 1997, 11, 1478-1481.

19. Ramanathan, R.; Prokai, L. Electrospray Ionization Mass Spectrometric Study of Encapsulation of Amino Acids by Cyclodextrins. J. Am. Soc. Mass Spectrom. 1995, 6, 866-871.

20. Ahn, S.; Ramirez, J.; Grigorean, G.; Lebrilla, C. B. Chiral Recognition in Gas-Phase Cyclodextrin:Amino-Acid Complexes-Is the Three Point Interaction Still Valid in the Gas Phase? J. Am. Soc. Mass Spectrom. 2001, 12, 278-287.

21. Cunniff, J. B.; Vouros, P. False Positives and the Detection of Cyclodextrin Inclusion Complexes by Electrospray Mass Spectrometry. J. Am. Soc. Mass Spectrom. 1995, 6, 437-447.

22. Sun, W.; Cui, M.; Liu, S.; Song, F.; Elkin, Y. N. Electrospray Ionization Mass Spectrometry of Cyclodextrin Complexes with Amino Acids in Incubated Solutions and in Eluates of Gel Permeation Chromatography. Rapid Commun. Mass Spectrom. 1998, 12, 2016-2022.

23. Penn, S. G.; He, F.; Lebrilla, C. B. Peptides Complexed to Cyclodextrin Fragment Rather than Dissociate when subjected to Blackbody Infrared Radiation. J. Phys. Chem. 1998, 102, 9119-9126.

24. Penn, S. G.; He, F.; Green, M. K.; Lebrilla, C. B. The Use of Heated Capillary Dissociation and Collision-Induced Dissociation to Determine the Strength of Noncovalent Bonding Interactions in Gas-Phase Peptide-Cyclodextrin Complexes. J. Am. Soc. Mass Spectrom. 1997, 8, 244-252.

25. Ramirez, H.; Ahn, S.; Grigorean, G.; Lebrilla, C. B. Evidence for the Formation of Gas-Phase Inclusion Complexes with Cyclodextrins and Amino Acids. J. Am. Chem. Soc. 2000, 122, 6884-6890.

26. Grigorean, G.; Ramirez, J.; Ahn, S. H.; Lebrilla, C. B. A Mass Spectrometry Method for the Determination of Enantiomeric Excess in Mixtures of D,L-Amino Acids. Anal. Chem. 2000, 72, 4275-4281. 
27. Brodbelt, J. S. Probing Molecular Recognition by Mass Spectrometry. Int. J. Mass Spectrom. 2000, 200, 57-69.

28. Blanda, M. T.; Farmer, D. B.; Brodbelt, J. S.; Goolsby, B. J. Synthesis and Alkali Metal Ion Binding Properties of Two Rigid Sterochemical Isomers of Calix[6]arene Bis-crown-4. J. Am. Chem. Soc. 2000, 122, 1486-1491.

29. Greig, M. J.; Gaus, H.; Cummins, L. L.; Sasmor, H.; Griffey, R. H. Measurement of Macromolecular Binding Using Electrospray Mass Spectrometry. Determination of Dissociation Constants for Oligonucleotide-Serum Albumin Complexes. J. Am. Chem. Soc. 1995, 117, 10765-10766.

30. Loo, J. A.; Hu, P.; McConnell, P.; Mueller, W. T.; Sawyer, T. K.; Thanabal, V. A Study of Src SH2 Domain Protein-Phosphopeptide Binding Interaction by Electrospray Ionization Mass Spectrometry. J. Am. Soc. Mass Spectrom. 1997, 8, 234243.

31. Lim, H. K.; Hsieh, Y. L.; Ganem, B.; Henion, J. Recognition of Cell Wall Peptide Ligands by Vancomycin Group Antibiotics: Studies Using Ion Spray Mass Spectrometry. J. Mass Spectrom. 1995, 30, 708-714.

32. Jorgensen, T. J. D.; Roepstorff, P.; Heck, A. J. R. Direct Determination of Solution Binding Constants for Noncovalent Complexes Between Bacterial Cell Wall Peptide Analogues and Vancomycin Group Antibiotics by Electrospray Ionization Mass Spectrometry. Anal. Chem. 1998, 70, 4427-4432.

33. Dunayevskiy, Y. M.; Lyubarskaya, Y. V.; Chu, Y. H.; Vouros, P.; Karger, B. L. Simultaneous Measurement of Nineteen Binding Constants of Peptides to Vancomycin Using Affinity Capillary Electrophoresis-Mass Spectrometry. J. Med. Chem. 1998, 41, 1201-1204.

34. Griffey, R. H.; Hofstadler, S. A.; Sannes-Lowery, K. A.; Ecker, D. J.; Crooke, S. T. Determinants of Aminoglycoside-Binding Specificity for rRNA by Using Mass Spectrometry. Proc. Natl. Acad. Sci. U.S.A. 1999, 96, 10129-10133.

35. Young, D. S.; Hung, H. Y.; Liu, L. K. An Easy and Rapid Method for Determination of Stability Constants by Electrospray Ionization Mass Spectrometry. Rapid Commun. Mass Spectrom. 1997, 11, 769-773.
36. Kempen, E. C.; Brodbelt, J. S. A Method for the Determination of Binding Constants by Electrospray Ionization Mass Spectrometry. Anal. Chem. 2000, 72, 5411-5416.

37. Li, Y. T.; Hsieh, Y. L.; Henion, J. D.; Ocain, T. D.; Schiehser, G. A.; Ganem, B. Analysis of the Energetics of Gas-Phase Immunophilin-Ligand Complexes by Ion Spray Mass Spectrometry. J. Am. Chem. Soc. 1994, 116, 7487-7493.

38. Blair, S. M.; Kempen, E. C.; Brodbelt, J. S. Determination of Binding Selectivities in Host-Guest Complexation by Electrospray/Quadrupole Ion Trap Mass Spectrometry. J. Am. Soc. Mass Spectrom. 1998, 9, 1049-1059.

39. Blair, S. M.; Brodbelt, J. S.; Reddy, G. M.; Marchand, A. P. Evaluation of Binding Selectivities of Bis-Crowned Clefts by Electrospray Ionization/Quadrupole Ion Trap Mass Spectrometry. J. Mass Spectrom. 1998, 33, 721-728.

40. Van Dorsselaer, A.; Bitsch, F.; Green, B.; Jarvis, S.; Lepage, P.; Bishoff, R.; Kolbe, H. V. J.; Roitsch, C. Application of Electrospray Mass Spectrometry to the Characterization of Recombinant Proteins up to $44 \mathrm{kDa}$. Biomed. Environ. Mass Spectrom. 1990, 19, 692-704.

41. Bruins, A. P. Mechanistic Aspects of Electrospray Ionization. J. Chromatogr. A 1998, 794, 345-357.

42. Dotsikas, Y.; Loukas, Y. L. Inclusional Complex Study Between 6-p-Toluidinylnaphthalene-2-Sulfonate and 2-Hydroxypropyl- $\beta$-Cyclodextrin. J. Biochem. Biophys. Methods 2002, $52,121-134$.

43. Gabelica, V.; Galic, N.; De Pauw, E. On the Specificity of Cyclodextrin Complexes Detected by Electrospray Mass Spectrometry. J. Am. Soc. Mass Spectrom. 2002, 13, 946-953.

44. Kobetić, R.; Jursic, B. S.; Bonnette, S.; Tsai, J. S. C.; Salvatore, S. J. Study of the Lorazepam-Cyclodextrin Inclusion Complexes Using Electrospray Ionization Mass Spectrometry. Tetrahedron Lett. 2001, 42, 6077-6082.

45. Zia, V.; Rajewski, R. A.; Stella, V. J. Thermodynamics of Binding of Neutral Molecules to Sulfobutyl Ether $\beta$-Cyclodextrins (SBE- $\beta$-CDs): The Effect of Total Degree of Substitution. Pharm. Res. 2000, 17, 936-941. 